\title{
Concentrative Transport of Antifolates Mediated by the Proton- Coupled Folate Transporter (SLC46A1); Augmentation by a HEPES Buffer
}

\author{
Rongbao Zhao, Mitra Najmi, Srinivas Aluri, David C. Spray, and I. David Goldman \\ Departments of Molecular Pharmacology (R.Z., M.N., S.A., I.D.G.), Medicine (R.Z., I.D.G.), and Dominick P. Purpura Department \\ of Neuroscience (D.C.S.), Albert Einstein College of Medicine, Bronx, New York
}

Received August 30, 2017; accepted January 8, 2018

\section{ABSTRACT}

The proton-coupled folate transporter (PCFT) is ubiquitously expressed in solid tumors to which it delivers antifolates, particularly pemetrexed, into cancer cells. Studies of PCFT-mediated transport, to date, have focused exclusively on the influx of folates and antifolates. This article addresses the impact of PCFT on concentrative transport, critical to the formation of the active polyglutamate congeners, and at $\mathrm{pH}$ levels relevant to the tumor microenvironment. An HeLa-derived cell line was employed, in which folatespecific transport was mediated exclusively by PCFT. At pH 7.0, there was a substantial chemical gradient for methotrexate that decreased as the extracellular $\mathrm{pH}$ was increased. A chemical gradient was still detected at $\mathrm{pH} 7.4$ in the usual HEPES-based transport buffer in contrast to what was observed in a bicarbonate/ $\mathrm{CO}_{2}$-buffered medium. This antifolate gradient correlated with an alkaline intracellular $\mathrm{pH}$ in the former $(\mathrm{pH} 7.85)$, but not the latter (pH 7.39), buffer and was abolished by the protonophore carbonyl cyanide-4-(trifluoromethoxy)phenylhydrazone. The gradient in HEPES buffer at $\mathrm{pH} 7.4$ was the result of the activity of $\mathrm{Na}^{+} / \mathrm{H}^{+}$ exchanger(s); it was eliminated by inhibitors of $\mathrm{Na}^{+} / \mathrm{H}^{+}$exchanger (s) or $\mathrm{Na}^{+} / \mathrm{K}^{+}$ATPase. An antifolate chemical gradient was also detected in bicarbonate buffer at $\mathrm{pH} 6.9$ versus 7.4 , also suppressed by carbonyl cyanide-4-(trifluoromethoxy)phenylhydrazone. When the membrane potential is considered, PCFT generates substantial transmembrane electrochemical-potential gradients at extracellular $\mathrm{pH}$ levels relevant to the tumor microenvironment. The augmentation of intracellular $\mathrm{pH}$, when cells are in a HEPES buffer, should be taken into consideration in studies that encompass all proton-coupled transporter families.

\section{Introduction}

The proton-coupled folate transporter (PCFT) is widely expressed in human epithelial cancers (Zhao et al., 2004a; Desmoulin et al., 2011). Its low optimum $\mathrm{pH}$ favors a role in the delivery of antifolates within the hypoxic, acidic microenvironment of tumors (Qiu et al., 2006; Zhao and Goldman, 2013b). This may be particularly relevant to pemetrexed, an agent that has a high affinity for this transporter, and may be the reason why tumor cells that develop resistance to methotrexate (MTX) owing to loss of reduced folate carrier function, retain sensitivity to pemetrexed (Zhao et al., 2004b; Chattopadhyay et al., 2006). Low expression of PCFT strongly correlates with poor outcome in patients with mesothelioma treated with pemetrexed (Giovannetti et al., 2017). PCFT is the sole carrier-mediated route of transport of a new generation of folate analogs that are inhibitors of purine synthesis (Matherly et al., 2018). PCFT's major physiologic role is in the intestinal absorption of folates and folate transport across the choroid plexus into the cerebrospinal fluid (Qiu et al., 2006; Zhao et al., 2009; Visentin et al., 2014). Mutations in the PCFT

This research was supported by the National Institutes of Health National Cancer Institute [CA82621].

https://doi.org/10.1124/mol.117.110445. gene that result in loss of function of the protein are the molecular basis for the rare autosomal recessive disorder, hereditary folate malabsorption (OMIN229050) in which both functions are impaired (Qiu et al., 2006; Kronn and Goldman, 2017; Zhao et al., 2017).

The major parameter of studies on PCFT-mediated transport has been the rate of transport into cells (influx). However, once in the cell MTX and pemetrexed form polyglutamate derivatives, mediated by folylpolyglutamate synthetase (FPGS), which are retained and build to high intracellular levels (Habeck et al., 1995; Zhao et al., 2004b). In the case of pemetrexed, the polyglutamate congeners are synthesized much more rapidly than MTX by FPGS and, in contrast to the monoglutamate, are the active derivatives that inhibit tetrahydrofolate cofactor-dependent enzymes required for de novo purine and thymidylate synthesis (Shih et al., 1997; Chattopadhyay et al., 2007). The rate and extent of polyglutamate formation is dependent upon the concentration of free drug achieved within the intracellular compartment. Hence, understanding the properties of PCFT-mediated transport that govern the transmembrane antifolate gradient and the level of free drug achieved in the intracellular compartment is critical from the pharmacological perspective. This is of

ABBREVIATIONS: BCECF-AM, 2',7'-bis-(2-carboxyethyl)-5-(and-6)-carboxyfluorescein, acetoxymethyl ester; EIPA, 5-( $N$-ethyl- $N$-isopropyl)amiloride; FCCP, carbonyl cyanide-4-(trifluoromethoxy)phenylhydrazone; FPGS, folylpolyglutamate synthetase; HBS, HEPES-buffered saline; MOPS, 4-morpholinepropanesulfonic acid; MTX, methotrexate; PCFT, proton-coupled folate transporter; RFC, reduced folate carrier. 
particular importance under the acidic conditions that exist within the microenvironment of tumors.

The present study focuses on the characterization of net transport of MTX, in particular, concentrative transport as a function of the $\mathrm{pH}$ gradient across the cell membrane. In the course of these studies chemical gradients for MTX were observed at neutral extracellular $\mathrm{pH}$ in Hela cells studied in a HEPES buffer system usually employed for transport studies. To understand the basis for this transport, and to exploit this phenomenon to better characterize PCFT-mediated net transport, studies were undertaken with an HeLa cell line transfected to express a high level of PCFT so that this transporter would be the dominant route of antifolate transport across the cell membrane. The data characterize PCFT-mediated concentrative transport for both MTX and pemetrexed generated by an inward proton gradient at modest extracellular acidic $\mathrm{pH}$ levels or under conditions of mild intracellular alkalization.

\section{Materials and Methods}

Key Chemicals. [ $\left.3^{\prime}, 5^{\prime}, 7-3 \mathrm{H}(\mathrm{N})\right] \mathrm{MTX}$ and generally tritium-labeled pemetrexed was obtained from Moravek Inc. (Brea, CA). Carbonyl cyanide-4-(trifluoromethoxy)phenylhydrazone (FCCP), 5-( $N$-ethyl- $N$ isopropyl)amiloride (EIPA), monensin, ouabain, and nigericin were purchased from Sigma-Aldrich (St. Louis, MO). BCECF-AM was obtained from Thermo Fisher Scientific (Waltham, MA).

Cells, Culture Conditions, and Transfections. R1-11-PCFT-h cells are stable PCFT transfectants that originate from HeLa cells and express a high level of PCFT but lack constitutive expression of reduced folate carrier (RFC) (Zhao et al., 2013). R1-11-RFC-6 cells are stable transfectants that also originate from HeLa cells and express constitutive levels of RFC but lack expression of PCFT (Zhao et al., 2008). These cells were derived from clonal lines and this, along with the very well defined antifolate $\mathrm{IC}_{50} \mathrm{~s}$, is consistent with homogeneous expression of PCFT or RFC (Zhao et al., 2008, 2014). R1-11 cells that do not express RFC and PCFT (Zhao et al., 2004a; Diop-Bove et al., 2009) were recipients of both stable transfections. All these cells were grown in RPMI-1640 medium supplemented with $10 \%$ fetal bovine serum, $100 \mathrm{IU} / \mathrm{ml}$ of penicillin, and $100 \mu \mathrm{g} / \mathrm{ml}$ streptomycin. Hygromycin $(0.3 \mathrm{mg} / \mathrm{ml})$ was added to the growth medium for R1-11-PCFT-h cells; zeocin $(0.1 \mathrm{mg} / \mathrm{ml})$ was included in the growth medium for R1-11RFC-6 cells to maintain carrier expression. For transient transfections, RFC or PCFT cDNAs constructed in pcDNA 3.1 were used as the expression vectors. R-11 cells were seeded in $20 \mathrm{ml}$ Low Background Glass Scintillation Vials (Research Products International, Prospect, IL) and transient transfections were conducted 2 or 3 days later with Lipofectamine 2000 (Invitrogen, Carlsbad, CA). Assessment of net MTX uptake was performed 2 days after transfection.

Membrane Transport. Two different buffer systems, previously employed in this laboratory, were used for transport studies: 1) HEPES-buffered saline (HBS; $20 \mathrm{mM}$ HEPES, $5 \mathrm{mM}$ dextrose, $140 \mathrm{mM} \mathrm{NaCl}, 5 \mathrm{mM} \mathrm{KCl}, 2 \mathrm{mM} \mathrm{MgCl} 2$ ) adjusted to $\mathrm{pH} \mathrm{7.0,} \mathrm{7.2,} \mathrm{7.4,}$ $7.6,7.8$, or 8.0 and 2) folate-free serum-free RPMI-1640 medium containing $24 \mathrm{mM}$ sodium bicarbonate at $\mathrm{pH}$ 7.3. The $\mathrm{pH}$ of the RPMI medium was adjusted to 6.9 by reducing the sodium bicarbonate concentration to $7.2 \mathrm{mM}$ (Zhao et al., 2004a). Serum-free RPMI medium is used in these studies to exclude binding of tritiated antifolates to serum proteins. Cells in both RPMI preparations were maintained in a $37^{\circ} \mathrm{C}$ incubator under an atmosphere of $5 \% \mathrm{CO}_{2}$ for at least 4 hours before experiments were initiated. For measurements of net uptake, cells that had been seeded in the glass scintillation vials and reached early confluency were washed twice with HBS (pH 7.4) or RPMI and incubated for 20 minutes either in HBS in a $37^{\circ} \mathrm{C}$ water bath or in RPMI at $37^{\circ} \mathrm{C}$ in a $\mathrm{CO}_{2}$ incubator. Uptake was initiated by replacing the buffer with $0.5 \mathrm{ml}$ prewarmed HBS or RPMI containing the desired concentration of tritiated drug. For assessment of the effects of FCCP, EIPA, ouabain, or monensin on net uptake, a small volume of $1000 \times$ stock solution either in dimethyl sulfoxide or ethanol was diluted in transport buffer with tritiated drug. Uptake was continued for 40 minutes at $37^{\circ} \mathrm{C}$, unless otherwise specified, following which $5 \mathrm{ml}$ of ice-cold HBS (pH 7.4) was added, the cells washed three times, then digested in $0.5 \mathrm{ml}$ of $0.2 \mathrm{M} \mathrm{NaOH}$ at $65^{\circ} \mathrm{C}$ for 1 hour. Radioactivity in $0.4 \mathrm{ml}$ of lysate was determined on a liquid scintillation spectrometer and normalized to the protein level obtained with the BCA Protein Assay (Pierce Protein Biology/Thermo Fisher Scientific). Net uptake of antifolates was expressed as picomoles per milligram protein or percentages of control. For some experiments units of picomoles per milligram protein were converted to intracellular concentration (micromolar) on the basis of the conversion factor $8.73 \mathrm{pmol} / \mathrm{mg}$ protein per micromolar (Sharif et al., 1998).

Intracellular pH Measurements. These measurements were obtained as previously described (Zhao et al., 2013). Briefly, R1-11PCFT-h cells grown in glass-bottom dishes (MatTek, Ashland, MA) were loaded with BCECF-AM, a $\mathrm{pH}$ indicator, $(10 \mu \mathrm{M}$, Molecular Probes/Invitrogen; Thermo Fisher Scientific) in culture media for 45 minutes at $37^{\circ} \mathrm{C}$ in a humidified $5 \% \mathrm{CO}_{2}$ incubator. Cells were then rinsed with prewarmed HBS or $5 \% \mathrm{CO}_{2}$-saturated RPMI and imaged at $37^{\circ} \mathrm{C}$ with an Orca-EM camera (Hamamatsu, Japan) attached to a Nikon TE2000 microscope. Changes in BCECF fluorescence intensity emitted at two excitation wavelengths (480 and $450 \mathrm{~nm}$ ) were acquired at $1.0 \mathrm{~Hz}$ using filters and shutter (Lambda DG-4; Sutter Instruments, Novato, CA) driven by a computer through MetaFluor software (Molecular Devices, Silicon Valley, CA). Intracellular $\mathrm{pH}$ was calibrated for each dish with MOPS-buffered $\mathrm{pH}$ solutions of $140 \mathrm{mM}$ potassium chloride and $20 \mu \mathrm{M}$ nigericin at $\mathrm{pH} 8.0$ or $\mathrm{pH} 7.0$.

\section{Results}

Transmembrane MTX Gradients as a Function of Extracellular pH. Studies were undertaken to assess the extent to which there is concentrative MTX transport as the $\mathrm{pH}$ of HEPES-based saline (HBS) increases from mildly acidic to the basic $\mathrm{pH}$ range. An HeLa cell line, R1-11-PCFT-h, was employed that lacks RFC expression but stably expresses a very high level of PCFT, so that it is the dominant mediator of MTX transport in these cells. The PCFT influx $\mathrm{K}_{\mathrm{t}}$ for MTX at $\mathrm{pH} 7.4$ is $\sim 100 \mu \mathrm{M}$ (Zhao et al., 2008); that concentration, at which the carrier is half-saturated, was used in these experiments. As indicated in Fig. 1, at pH 7.0, the net intracellular MTX concentration exceeded that of the extracellular compartment by a factor of 5 . When the $\mathrm{pH}$ gradient across the cell membrane was collapsed with FCCP, a proton ionophore (Benz and McLaughlin, 1983), intracellular MTX fell to a level $(100 \mu \mathrm{M})$ equal to the extracellular MTX concentration. As the extracellular $\mathrm{pH}$ was increased, the transmembrane MTX gradient decreased, but there was still a 2.1-fold chemical gradient for MTX even at an extracellular $\mathrm{pH}$ of 7.4. As the $\mathrm{pH}$ was increased further to 8 , the transmembrane MTX gradient continued to fall, reversing beyond $\mathrm{pH}$ 7.6. As the $\mathrm{pH}$ increased and the MTX gradient decreased, FCCP continued to suppress the intracellular MTX level but the percentage of change decreased. Overall, there was a 22 -fold decrease in net MTX uptake over the $1 \mathrm{pH}$-unit increase of from seven to eight. Even between $\mathrm{pH} 7.20$ and 7.60, there was a 3.5-fold difference in the net MTX level. Studies were then undertaken to explore the basis for the transmembrane gradient at neutral extracellular $\mathrm{pH}$ in the HBS buffer system. 


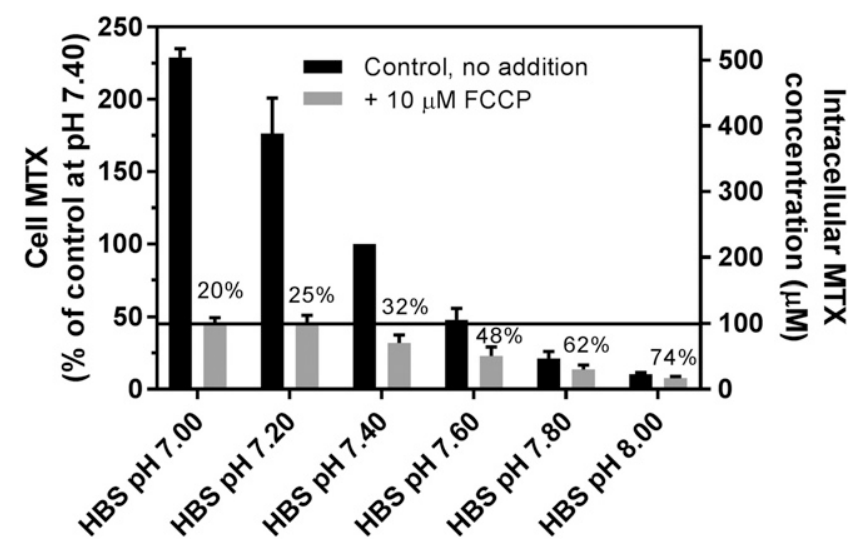

Fig. 1. The MTX transmembrane gradient as a function of extracellular $\mathrm{pH}$ in cells incubated in HBS. After a 20-minute preincubation of R1-11PCFT-h cells in HBS (pH 7.40), $\left[{ }^{3} \mathrm{H}\right] \mathrm{MTX}$ was added to achieve a concentration of $100 \mu \mathrm{M}$, and uptake continued for 40 minutes in the presence or absence of $10 \mu \mathrm{M}$ FCCP in HBS over a range of $\mathrm{pH}$ values. Net uptake of MTX in HBS (pH 7.40) in the absence of FCCP was set as $100 \%$ as a basis for comparison. The percentage of uptake in the presence vs. absence of FCCP is indicated above the bars for each $\mathrm{pH}$. The intracellular MTX concentrations in units of micromolarity are indicated in the right $Y$-axis. The horizontal line indicates the extracellular MTX concentration at $100 \mu \mathrm{M}$. Data are the mean \pm S.D. from three separate experiments.

Analysis of Net PCFT-Mediated MTX Transport When the Extracellular pH Is Neutral; Impact of the Buffer. To assess whether HEPES-buffered HBS might impact upon PCFT-mediated transmembrane MTX gradients, net transport was compared 10-50 minutes after addition of ${ }^{3} \mathrm{H}-\mathrm{MTX}$ in two buffer systems: 1) HBS (pH 7.40), which is HEPES-buffered and does not contain $\mathrm{NaHCO}_{3}$, and 2) folateand serum-free RPMI 1640 medium buffered with $24 \mathrm{mM}$ bicarbonate and maintained in an atmosphere of $5 \% \mathrm{CO}_{2}$ at an extracellular $\mathrm{pH}$ of 7.3. As indicated in Fig. 2, net MTX uptake reached $75 \%$ of steady state in HBS by 25 minutes, rising to a steady state by 40 minutes, whereas MTX uptake in RPMI was at steady state by 25 minutes at one-third the level in HBS. Inclusion of $10 \mu \mathrm{M}$ FCCP markedly decreased net MTX in cells in HBS. FCCP resulted in a smaller decrease in net MTX in the RPMI buffer. Hence, the difference in net MTX levels in cells maintained in the different buffers was substantially decreased when the proton gradient was abolished by FCCP.

When the intracellular MTX level is expressed in micromoles per liter, as in the right $Y$-axis of Fig. 2, it can be seen there was an approximately 3:1 chemical gradient for MTX in HBS that disappeared in the presence of FCCP. In RPMI there was no chemical gradient in the absence of FCCP and the net level was about half that of the extracellular concentration in the presence of FCCP. Hence, net MTX transport was concentrative primarily in HBS at $\mathrm{pH}$ 7.4. This difference in net MTX transport correlated with the difference in intracellular $\mathrm{pH}$ as assessed with BCECF dye. As indicated in Fig. 3, the intracellular $\mathrm{pH}$ in HBS [7.85 \pm 0.18 (mean \pm S.D.), $n=6$, Fig. 3A] was $\sim 0.46 \mathrm{pH}$ units higher than cells in RPMI [pH $7.39 \pm 0.19$ (mean \pm S.D. $), n=3$, Fig. $3 \mathrm{~B}(P=0.010$, unpaired two-tailed $t$ test)]. Hence, despite the fact that the extracellular $\mathrm{pH}$ was nearly the same in the two buffers, there was a substantial inward proton gradient in HBS, whereas a proton gradient could not be detected in cells in RPMI.

Mechanism of Intracellular Alkalinization in HEPES-Buffered Medium. Studies were undertaken to determine the basis for the increased intracellular $\mathrm{pH}$

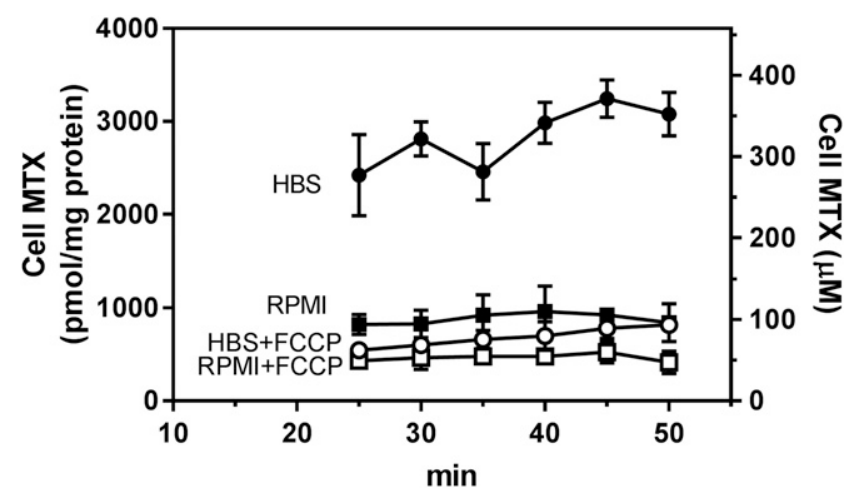

Fig. 2. Time course of net MTX uptake. R1-11-PCFT-h cells were washed twice with HBS ( $\mathrm{pH} 7.4$ ) or RPMI and preincubated in the respective buffers for 20 minutes in a $37^{\circ} \mathrm{C}$ water bath or in a $\mathrm{CO}_{2}$ incubator, respectively. Cells were then exposed to HBS or RPMI containing $\left[{ }^{3} \mathrm{H}\right] \mathrm{MTX}$ $(100 \mu \mathrm{M})$ over $10-50$ minutes in the presence or absence of $10 \mu \mathrm{M}$ FCCP. Net uptake is expressed as units of picomoles per milligram protein (left $Y$ axis) or units of micromoles per liter of intracellular water (right $Y$-axis). The data are the mean \pm S.D. from three independent experiments.

detected in the HBS buffer. The initial focus was on $\mathrm{Na}^{+} / \mathrm{H}^{+}$ antiporters that contribute to the maintenance of intracellular $\mathrm{pH}$ by exporting protons in exchange for sodium ions. EIPA $(10 \mu \mathrm{M})$, a specific inhibitor of $\mathrm{Na}^{+} / \mathrm{H}^{+}$antiporters (Masereel et al., 2003), decreased the net MTX level in cells in HBS by $77 \%$, whereas EIPA had no effect on the net MTX level in cells in RPMI (Fig. 4A). Likewise, a decrease in the $\mathrm{Na}^{+}$and $\mathrm{K}^{+}$ gradients by inhibition of the $\mathrm{Na}^{+} / \mathrm{K}^{+}$ATPase with $10 \mu \mathrm{M}$ ouabain also markedly reduced net MTX uptake in cells in HBS. Finally, although monensin $(50 \mu \mathrm{M})$, a sodium/proton exchanger (Nakazato and Hatano, 1991), did not alter net MTX uptake in HBS, the net MTX level more than doubled in RPMI. These observations suggested that the inward proton gradient in cells in HBS was generated by $\mathrm{Na}^{+} / \mathrm{H}^{+}$antiporters and sustained by the ATPase-dependent sodium gradient.

To explore the basis for the augmentation of net MTX uptake by monensin in cells in the RPMI buffer, the impact of the addition of other agents in the presence of monensin was assessed. As indicated in Fig. 4B, net MTX uptake in HBS was $\sim 2.3$-fold higher than in RPMI in these experiments. Monensin at $50 \mu \mathrm{M}$ increased net MTX uptake in RPMI to the level achieved in HBS. This was unchanged in the presence of EIPA but was abolished by FCCP or ouabain declining to the level with FCCP alone. In contrast to the marked reduction in MTX uptake induced by EIPA in the absence of monensin cells in HBS, EIPA had no effect at all on MTX uptake in the presence of monensin either in cells in HBS or RPMI.

Potential Role of ABC Exporters in the Modulation of Net MTX Levels. The net level of free intracellular folates and antifolates is determined by the balance between the carriers PCFT or RFC, which generates an inward gradient, and by several $\mathrm{ABC}$ exporters, such as multidrug-resistant proteins that pump folates/antifolates out of cells (Assaraf, 2006). Hence, changes in net MTX levels observed with these inhibitors might be explained, in part, by their effects on ABC exporters. The high level of expression of PCFT in these cells was designed to decrease the impact of $\mathrm{ABC}$ exporters. However, further studies were designed to assess possible changes in $\mathrm{ABC}$ exporters that impact upon the assessment of PCFT-mediated net antifolate levels. Effects of alterations in $\mathrm{ABC}$ exporter function should also be observed under 


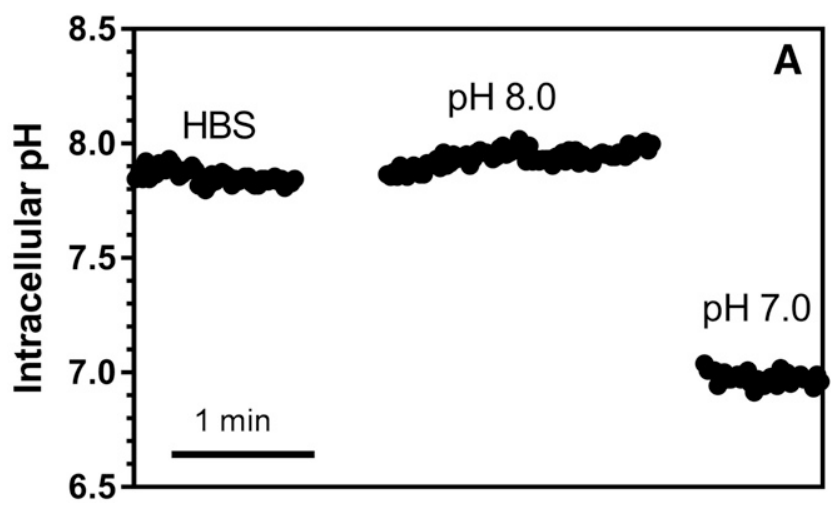

Time

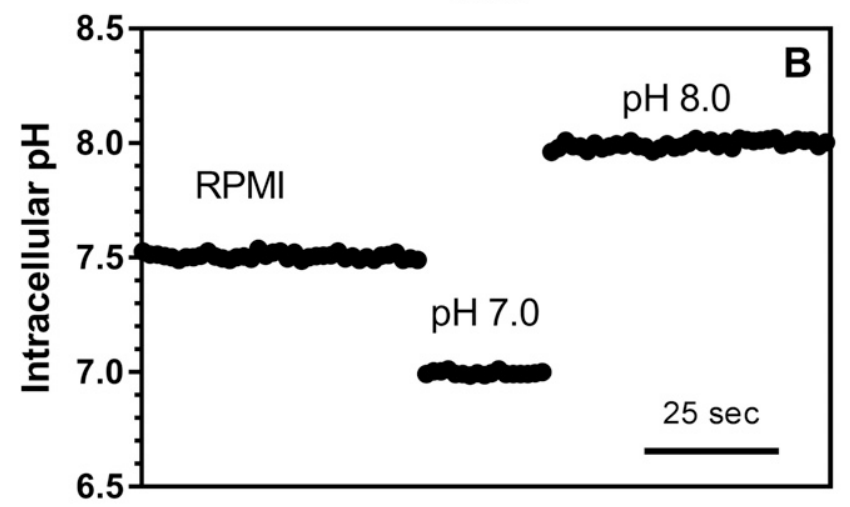

Time

Fig. 3. Representative measurements of intracellular $\mathrm{pH}$ in cells incubated in $\mathrm{HBS}$ or RPMI/CO 2 . R1-11-PCFT-h cells grown in RPMI medium were loaded with the fluorescent dye BCECF in the growth medium. The cells were then thoroughly rinsed with prewarmed $\mathrm{HBS}$ or $5 \% \mathrm{CO}_{2-}$ saturated RPMI. Intracellular $\mathrm{pH}$ was recorded until constant and calibrated for each slide with two $\mathrm{pH}$ standards (pH 7.0 and 8.0). (A) Cells incubated in HBS. The values are the mean from measurements in eight different cells. (B) Cells incubated in $\mathrm{RPMI} / \mathrm{CO}_{2}$. The values are the mean from measurements in four different cells.

conditions in which the net level of intracellular antifolates is mediated solely by RFC, a folate/organic phosphate antiporter (Assaraf, 2006). To evaluate this, the impact of these agents was assessed in R1-11-RFC-6 cells that do not express PCFT but stably express RFC at levels comparable to that of wildtype HeLa cells. Any contribution of the ABC exporters to the net MTX level should overwhelm the low level of MTX cycling mediated by RFC under these conditions. As indicated in Fig. 5A, there was no significant difference in RFC-mediated steady-state MTX levels in RPMI and, beyond a very small decrease ( $15 \%, P=0.029$, paired two-tailed $t$ test) in the EIPAtreated cells, none of these agents altered net MTX uptake mediated by RFC in the cells in HBS. Hence, the data were consistent with effects of these agents on R1-11-PCFT-h cells owing specifically to effects on PCFT-mediated transport and were unrelated to alterations in $\mathrm{ABC}$ exporter activities.

To further exclude the possibility that the effects of FCCP, EIPA, or ouabain on net MTX uptake observed in PCFT and RFC stable transfectants were related to possible differences in the expression of $\mathrm{ABC}$ exporters, the impact of these inhibitors on net MTX uptake was assessed in RFC- and PCFT-transient transfectants using the same promoter and exactly the same conditions. Under these conditions,
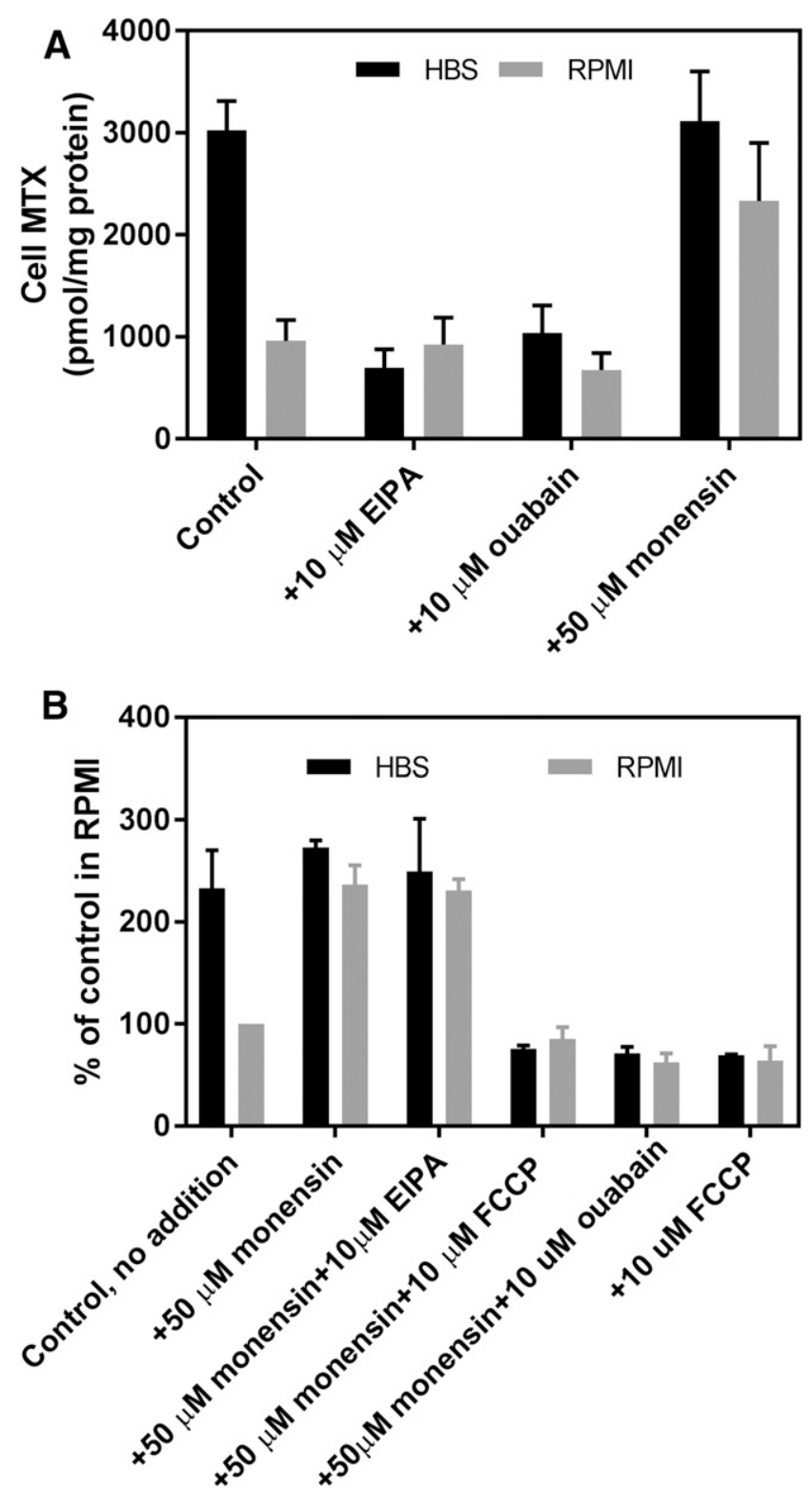

Fig. 4. Effects of EIPA, ouabain, or monensin, alone, or in combination on net MTX levels in R1-11-PCFT-h cells incubated in HBS ( $\mathrm{pH} 7.40$ ) or RPMI (pH 7.3). (A) Net MTX uptake $(100 \mu \mathrm{M})$ was assessed after 40 minutes with and without EIPA $(10 \mu \mathrm{M})$, ouabain $(10 \mu \mathrm{M})$, or monensin $(50 \mu \mathrm{M})$ added simultaneously with $\left.{ }^{3} \mathrm{H}\right] \mathrm{MTX}$. Cell MTX is expressed in units of picomoles per milligram protein. (B) Net MTX uptake (100 $\mu \mathrm{M})$ was assessed after 40 minutes in the presence of monensin $(50 \mu \mathrm{M})$ with and without EIPA $(10 \mu \mathrm{M})$, ouabain $(10 \mu \mathrm{M})$, or FCCP $(10 \mu \mathrm{M})$ added simultaneously with $\left[{ }^{3} \mathrm{H}\right]$ MTX. Net MTX uptake in RPMI without any addition was set as $100 \%$ as a basis for comparison. Data in both panels are the mean \pm S.D. from three independent experiments.

expression of $\mathrm{ABC}$ exporters in both transient transfectants should have been comparable. As indicated in Fig. 5B, transfections of either RFC or PCFT increased net MTX uptake compared with the mock transfection. However, FCCP, EIPA, and ouabain did not significantly alter net MTX uptake in RFC transient transfects, whereas these agents reduced MTX net uptake by more than $50 \%$ in PCFT transient transfectants $(P<0.05)$. The lesser effects on net MTX uptake by these reagents observed in PCFT-transient transfectants compared with the PCFT-stable transfectants is 


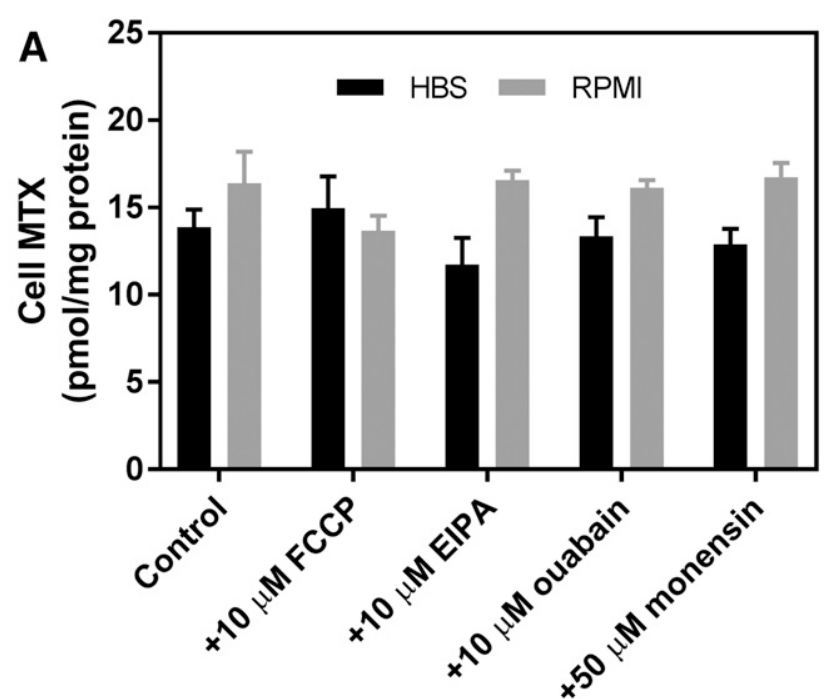

B

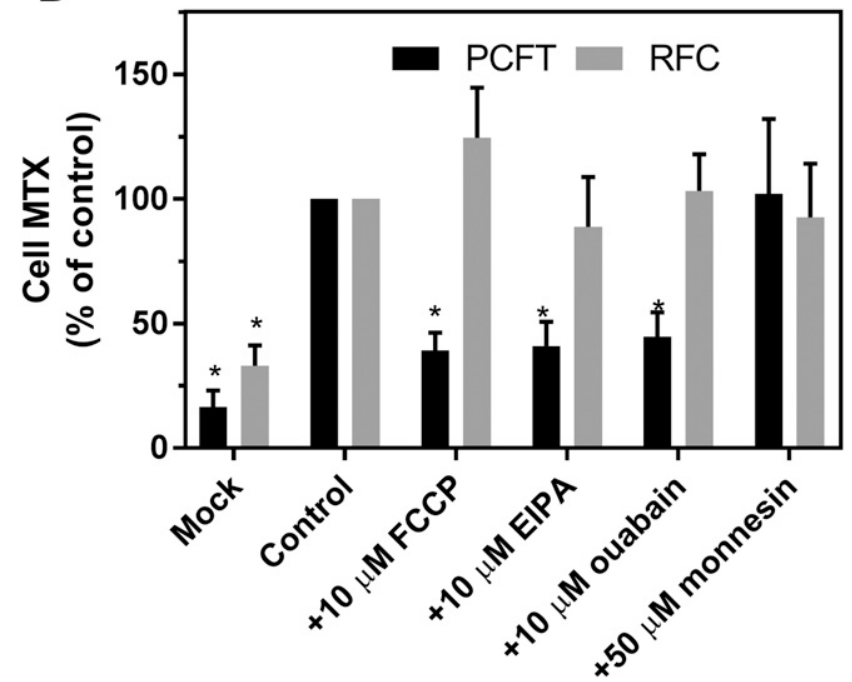

Fig. 5. Effects of FCCP, EIPA, ouabain, or monensin on net MTX levels in RFC stable transfectants (A) and transient transfectants of RFC or PCFT (B). (A) Net uptake of MTX ( $5 \mu \mathrm{M})$ in R1-11-RFC-6 cells incubated in HBS at pH 7.40 or RPMI at pH 7.3 for 40 minutes. (B) Net uptake of MTX in RFC $(5 \mu \mathrm{M})$ - or PCFT $(100 \mu \mathrm{M})$-transient transfectants in HBS at $\mathrm{pH} 7.40$ for 40 minutes. FCCP $(10 \mu \mathrm{M})$, EIPA $(10 \mu \mathrm{M})$, ouabain $(10 \mu \mathrm{M})$, or monensin $(50 \mu \mathrm{M})$ was added simultaneously with $\left[{ }^{3} \mathrm{H}\right] \mathrm{MTX}$. For (B), the data are expressed as percentages of control, which is $11 \pm 2$ and $300 \pm 52$ (mean \pm S.D.) $\mathrm{pmol} / \mathrm{mg}$ protein for $\mathrm{RFC}$ and PCFT transient transfectants, respectively. Asterisks indicate that the values are significantly different from the control on the basis of a paired two-tailed $t$ test $(P<0.5)$. Data are the mean \pm S.D. from three $(\mathrm{A})$ and four $(\mathrm{B})$ independent experiments.

probably related to the difference in MTX net uptake ( $\sim 300$ $\mathrm{pmol} / \mathrm{mg}$ vs. $\sim 3000 \mathrm{pmol} / \mathrm{mg}$ protein for transient and stable transfectants, respectively). As observed with the stable transfectants, monensin had no effect on net MTX uptake for either RFC or PCFT transient transfectants. The lack of an impact by these inhibitors on net MTX uptake mediated by $\mathrm{RFC}$ in the transient transfectants is additional evidence that the effects of FCCP, EIPA, and ouabain on net MTX uptake are entirely the result of changes in PCFT-mediated transport and are not related to alterations in expression of $\mathrm{ABC}$ exporters.

Net Transport of Pemetrexed, Effects of Buffers Monensin and FCCP. Net transport of pemetrexed was

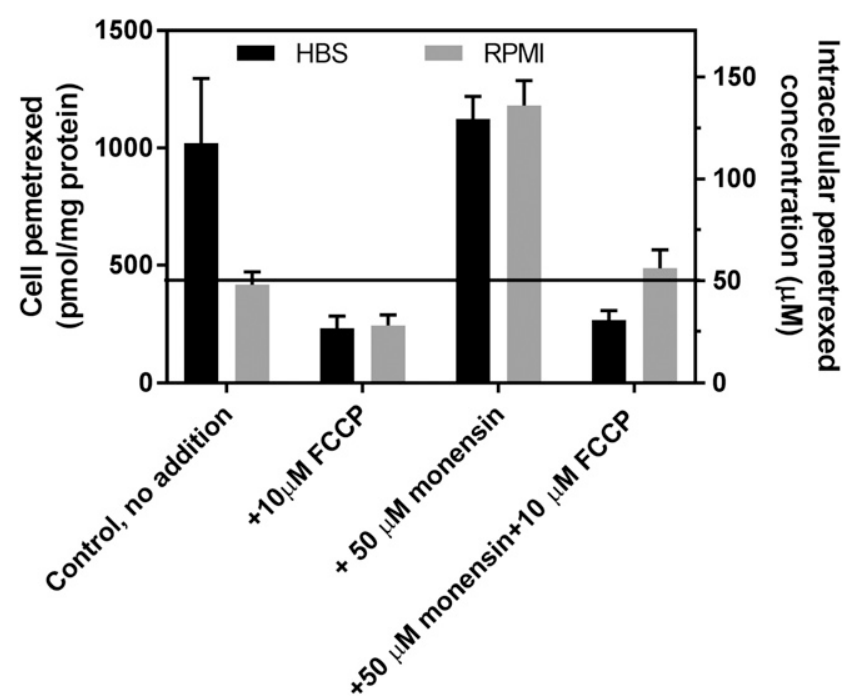

Fig. 6. Effects of monensin, FCCP, or in combination on net uptake of pemetrexed. Net uptake of pemetrexed $(50 \mu \mathrm{M})$ was assessed over 40 minutes; the reagents were added simultaneously with $\left[{ }^{3} \mathrm{H}\right]$ pemetrexed in HBS ( $\mathrm{pH} 7.40$ ) or RPMI ( $\mathrm{pH} 7.3$ ). Net intracellular pemetrexed is expressed as picomoles per milligram protein (left $Y$-axis) and micromoles per liter intracellular water (right $Y$-axis). The horizontal line indicates an extracellular pemetrexed concentration of $50 \mu \mathrm{M}$. Data are the mean \pm S.D. from three independent experiments for both panels.

also assessed in HBS or RPMI in the presence or absence of monensin and FCCP. Pemetrexed forms polyglutamate derivatives that are retained within cells and accumulate much more rapidly than MTX. This complicates discrimination between monoglutamate, free within the intracellular water, and tritiated polyglutamylated congeners that cannot exit the cells. To address this, in preparation for experiments, R1-11PCFT-h cells were grown with $0.1 \mathrm{mM}$ folic acid overnight to allow accumulation of reduced folate derivatives that are good substrates for FPGS and compete with, and suppress, the polyglutamation of pemetrexed. Net $\left[{ }^{3} \mathrm{H}\right]$ pemetrexed uptake was then assessed at $50 \mu \mathrm{M}$ (the influx $\mathrm{K}_{\mathrm{i}}$ for pemetrexed at $\mathrm{pH} 7.4$ is $12-15 \mu \mathrm{M})$ for 40 minutes. This concentration is also relevant to pemetrexed blood levels after intravenous administration of the drug (Latz et al., 2006). As indicated in Fig. 6, and as was observed for MTX, net pemetrexed uptake in HBS was 2.5-fold greater than in RPMI at $\mathrm{pH}$ 7.4. Monensin increased pemetrexed net transport in RPMI by a factor of about 2.5 but did not affect net pemetrexed uptake in HBS. FCCP decreased the net pemetrexed level to $\sim 25 \mu \mathrm{M}$, one-half the extracellular level in either buffer, and also suppressed the increase observed with monensin in RPMI.

Analysis of Net Intracellular MTX Transport in RPMI at pH 7.3 Versus 6.9. To better simulate conditions within the microenvironment of solid tumors in vivo, using a physiologic buffered system, MTX levels were evaluated in cells in RPMI at $\mathrm{pH} 7.3$ and RPMI adjusted to a $\mathrm{pH}$ of 6.9 by decreasing the bicarbonate concentration to $7.2 \mathrm{mM}$ in a $5 \%$ $\mathrm{CO}_{2}$ atmosphere, in the presence or absence of FCCP, ouabain, EIPA, or monensin. As indicated in Fig. 7, the net intracellular MTX level nearly doubled at $\mathrm{pH} 6.9$ versus 7.3 . When the membrane potential is considered, this represents a substantial electrochemical-potential gradient for MTX. FCCP resulted in a decline in the net intracellular MTX levels to a comparable level in both buffers at approximately half that at 


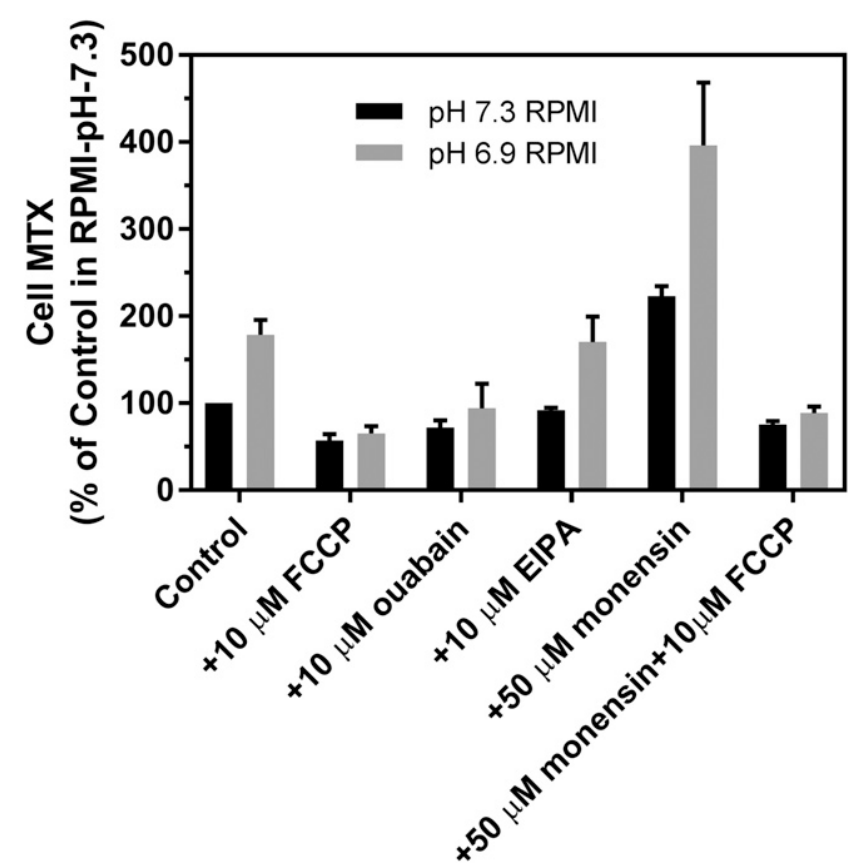

Fig. 7. A comparison of steady-state MTX levels in cells in RPMI at pH 6.9 vs. 7.4 and the effects of FCCP, ouabain, EIPA, or monensin. The $\mathrm{pH}$ was decreased to 6.9 by lowering the bicarbonate concentration to $7.2 \mathrm{mM}$ with the cells maintained in $5 \% \mathrm{CO}_{2}$. Cells were incubated with $\left.100 \mu \mathrm{M}{ }^{3} \mathrm{H}\right]$ MTX for 40 minutes in the absence or presence of FCCP, ouabain, EIPA, monensin, or a combination of monensin and FCCP. The intracellular MTX level in RPMI (pH 7.3) is indicated as 100\%. Data are the mean \pm S.D. from three independent experiments.

$\mathrm{pH}$ 7.3. The addition of monensin resulted in a 2.2 -fold increase in the MTX level at both $\mathrm{pH} 6.9$ and 7.3 that was abolished by FCCP. As a result, a combination of lower extracellular $\mathrm{pH}$ and the presence of monensin resulted in a 4-fold augmentation in the intracellular MTX level in RPMI. EIPA had no effect at either $\mathrm{pH}$, whereas ouabain decreased the MTX level at $\mathrm{pH} 6.9$ near to that at $\mathrm{pH} 7.4$.

\section{Discussion}

Studies of solute transporters usually focus on initial uptake properties. This may provide sufficient information for equilibrating systems that do not generate transmembrane gradients. However, the properties of transporters that generate gradients by the coupled flow of other ions or organic solutes is more complex. The free intracellular substrate level achieved may not be critical for some pharmacological agents, particularly when influx is rate-limiting to an important intracellular event. However, this parameter of the drug-cell interaction controlled by the membrane transporter is considerably more important when substantial levels of free intracellular drug are necessary to drive a subsequent biochemical step critical for drug retention, metabolism to an active derivative(s), or, in the case of a physiologic substrate, its normal cellular metabolism. This is the case for virtually all antifolate drugs now in the clinic, in particular pemetrexed, which requires polyglutamylation for its activity (Habeck et al., 1995; Shih et al., 1997), and a new generation of glycinamide ribonucleotide transformylase inhibitors with an equally high affinity for PCFT but a very low affinity for RFC (Desmoulin et al., 2012;
Hou et al., 2017). The latter agents are only active in their polyglutamate forms.

Studies of the concentrative potential of PCFT, in cells that typically exist in the normal systemic environment where the $\mathrm{pH}$ is maintained at 7.4 , are complicated by the rapid acidification of many cell types after exposure to acidic conditions. However, we demonstrate here that modest alkalinization of cells, under conditions in which the extracellular $\mathrm{pH}$ is at the normal systemic level, as occurs in HEPESbuffered media, results in a chemical gradient for MTX and pemetrexed. Hence, although the intracellular $\mathrm{pH}$ is essentially the same as the extracellular $\mathrm{pH}$ in RPMI medium, the intracellular $\mathrm{pH}$ is $0.46 \mathrm{pH}$ units higher when cells are incubated in a HEPES buffer under conditions used for most transport studies. The chemical gradients for MTX and pemetrexed are abolished with FCCP, suggesting that in the HEPES buffer they are driven, entirely, by a $\mathrm{pH}$ gradient across the cell membrane.

Hela cells have a substantial negative membrane potential, $\sim 50 \mathrm{mV}$, and MTX and pemetrexed carry negative charges at each carboxyl group in the glutamate moiety. Hence, at thermodynamic equilibrium, when there is no electrochemical-potential difference across the cell membrane, the concentration of these antifolates within the cell should be far below their extracellular concentration. For instance, assuming MTX to be a bivalent anion and the membrane potential to be $\sim 50 \mathrm{mV}$ (Stein et al., 1996), a reverse gradient is expected of $\sim 0.3[\mathrm{MTX}]_{\mathrm{i}} /[\mathrm{MTx}]_{\mathrm{e}}$. Accordingly, when the ratio of intracellular-to-extracellular concentration is one, there is in fact a 3-fold electrochemical-potential gradient across the cell membrane. This is consistent with the observation that the addition of FCCP results in intracellular MTX levels that are below the extracellular concentration. It is also of interest that FCCP appears to decrease net intracellular MTX in the bicarbonate-buffered system even under conditions in which there should not be a proton gradient. Beyond abolishing the proton gradient across the cell and mitochondrial membranes, FCCP also lowers the membrane potential (Park et al., 2002) which should increase, rather than decrease, net MTX levels. As FCCP also inhibits oxidation, this too would increase cellular MTX levels by decreasing ATP-dependent multidrug-resistant protein activity. Finally, although there are solute transporters that exhibit proton coupling at acidic $\mathrm{pH}$ and $\mathrm{Na}^{+}$coupling at neutral pH (Smith et al., 2005; Young et al., 2013), so that transmembrane gradients are present at neutral $\mathrm{pH}$, there is no evidence that PCFT is $\mathrm{Na}^{+}$-coupled at neutral $\mathrm{pH}$ and thus not responsible in part for the gradients observed (Zhao et al., 2013).

The data indicate that the chemical gradients observed for MTX and pemetrexed in HBS buffer result from a $\mathrm{pH}$ gradient generated by $\mathrm{Na}^{+} / \mathrm{H}^{+}$antiporter(s). Maintenance of the $\mathrm{Na}^{+}$ gradient, which drives the $\mathrm{Na}^{+} / \mathrm{H}^{+}$exchange, requires $\mathrm{Na}^{+}$ $/ \mathrm{K}^{+}$ATPase activity (Fig. 8). Hence, both EIPA and ouabain completely eliminate the antifolate gradient. Interestingly, monensin, an ionophore that functions as a Na${ }^{+} / \mathrm{H}^{+}$exchanger (Nakazato and Hatano, 1991), does not further increase net transport of MTX in cells in HBS, presumably because the proton gradient already present was generated by the constitutive $\mathrm{Na}^{+} / \mathrm{H}^{+}$exchanger(s). On the other hand, the monensin-induced MTX gradient in cells in RPMI is consistent with monensin acting as a $\mathrm{Na}^{+} / \mathrm{H}^{+}$exchanger to result in 


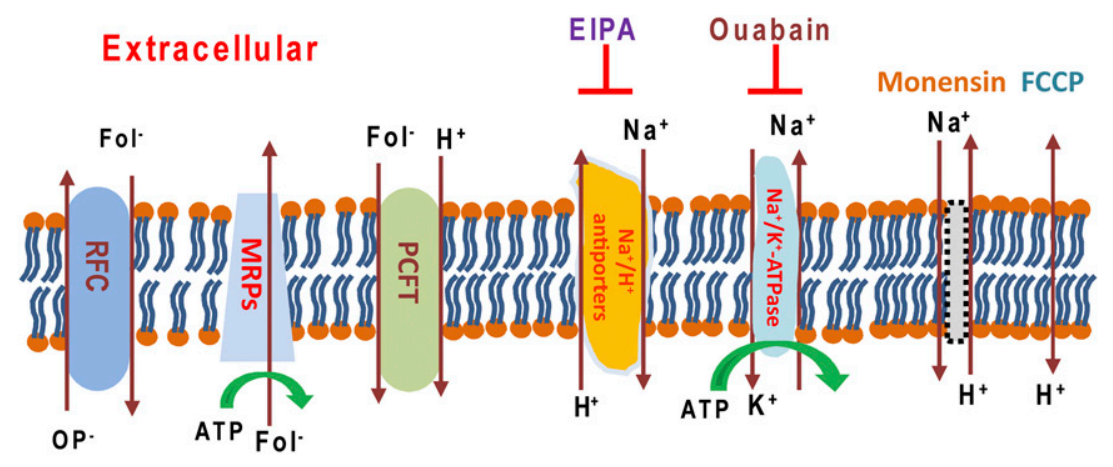

Intracellular

Fig. 8. Illustration of the transporters that impact upon the proton gradient and PCFT-mediated net folate/antifolate levels in cells. In R1-11-PCFT-h cells, RFC is absent whereas PCFT is overexpressed. At the steady state, influx of MTX is mediated solely by PCFT; efflux is mediated largely by PCFT owing to its extremely high level of expression. While multidrug-resistant proteins pump folates out of cells, their activity should be decreased relative to PCFT under these experimental conditions. In HEPES-based buffer, an inward proton gradient is the basis for the MTX or pemetrexed gradient mediated by PCFT at $\mathrm{pH} 7.4$. Na $/ \mathrm{K}^{+}$-ATPase provides the sodium gradient that drives the export of $\mathrm{H}^{+}$in exchange for $\mathrm{Na}^{+}$via $\mathrm{Na}^{+} / \mathrm{H}^{+}$antiporter(s), resulting in the intracellular alkalization. Either inhibition of $\mathrm{Na}^{+} / \mathrm{K}^{+}$-ATPase by ouabain or suppression of $\mathrm{Na}^{+} / \mathrm{H}^{+}$antiporters by EIPA diminishes $\mathrm{H}^{+}$export, decreasing the inward proton gradient at neutral $\mathrm{pH}$. In the presence of monensin, which functions as $\mathrm{Na}^{+} / \mathrm{H}^{+}$exchanger, the activity of the Na $/ \mathrm{H}^{+}$ antiporters is obviated. FCCP is a proton ionophore that eliminates the proton gradient.

a proton gradient that is abolished by FCCP and ouabain but is unaffected by EIPA. Although it would have been of interest to determine whether these changes in net MTX uptake are associated with changes in the antitumor activities of the antifolates, the intrinsic toxicity of these agents precluded an assessment of antifolate growth inhibition or cytotoxicity under these conditions.

Steady-state levels of folates and antifolates are determined by a variety of processes. Under physiologic conditions at $\mathrm{pH}$ 7.4, RFC transports folates into and out of virtually all systemic cells and has concentrative capability through an exchange with intracellular organic phosphates, in particular, adenine nucleotides (Zhao and Goldman, 2013a). The concentrative impact of both PCFT and RFC is opposed by several $\mathrm{ABC}$ exporters that transport the monoglutamate (and in some cases the lower polyglutamate derivatives) of folates and antifolates out of cells (Assaraf, 2006). The experimental design in the present study precluded an RFC contribution to the net antifolate level in these cells since they express only high levels of PCFT. A potential role for the ABC exporters as determinants of changes in concentrative transport under the various experimental conditions was excluded by the observation that there were essentially no differences in net uptake between the two buffers or with the various agents studied when MTX was delivered to the cells by RFC alone. Hence, the data indicate that the concentrative transport observed in HBS, and the effects of the various reagents, was mediated solely by PCFT, a proton-coupled process, and reflected changes in the transmembrane $\mathrm{pH}$ gradient. In a previous study, bicarbonate was shown to inhibit PCFT-mediated MTX influx in HBS buffer at neutral $\mathrm{pH}$ (Zhao et al., 2013). Although this was attributed to a direct inhibition of PCFT by bicarbonate, the present studies suggest that the decrease in initial uptake observed was most probably owing to the decrease in the proton gradient that occurs when bicarbonate is added to a HEPES-buffered system and the $\mathrm{CO}_{2}$ released that diffuses in, and acidifies, the cells (Levraut et al., 2001).

A HEPES-based buffer is generally used for membrane transport studies, obviating the complexity of a more physiologic bicarbonate system that requires maintenance of cells in $\mathrm{CO}_{2}$. The latter can be particularly cumbersome when initial rates are determined in cells growing in monolayer cultures. HBS has been used exclusively in studies of the membrane transport of folates and antifolates mediated by PCFT and RFC in human cells. The present study demonstrates an important difference in net antifolate levels between a HEPES-based and a bicarbonate buffered system (RPMI), observations that should be relevant to the study of other proton-coupled processes as well (Anderson and Thwaites, 2010). This phenomenon has been observed in other cell systems. For instance, an inward proton gradient was also found to be the result of a higher intracellular then extracellular $\mathrm{pH}(0.2-0.3$ units) for rat cerebellar Purkinje cells or rabbit ciliary body epithelium when a bicarbonate/ $\mathrm{CO}_{2}$ buffer was replaced with HEPES-based buffer (Gaillard and Dupont, 1990; Wolosin et al., 1991). The increase in intracellular $\mathrm{pH}$ that occurs when a bicarbonate buffer is replaced with a HEPES buffer is a consequence of the rapid diffusion of $\mathrm{CO}_{2}$ out of cells, which produces transient intracellular alkalosis. This is followed by a more sustained increased proton export activity owing to the $\mathrm{Na}^{+} / \mathrm{H}^{+}$exchanger(s) (Gaillard and Dupont, 1990) as observed in the present study.

As yet incompletely understood is the role that PCFT plays as a route of delivery of contemporary antifolates into cancer cells, in particular, pemetrexed, an agent with high affinity for this transporter. It is clear that PCFT can sustain the activity of pemetrexed when RFC is deleted, complemented by the concurrent contraction of cellular folates that enhances the polyglutamation of this agent (Zhao et al., 2004b; Chattopadhyay et al., 2006). This is probably the basis for the observation that it is very difficult, if not impossible, for cells to develop resistance to this drug because of a failure of transport into cells, which would require the loss of two genetically distinct transporters. PCFT is the sole solute transporter that mediates the activity of six-substituted pyrrolo[2,3-d]pyrimidine antifolate purine synthesis inhibitors that are very poor substrates for RFC (Desmoulin et al., 2012; Hou et al., 2017). The latter is a strategy for 
circumventing the toxicity of classic antifolates that is mediated primarily by their delivery into susceptible cells of the gastrointestinal tract and bone marrow by RFC. The pemetrexed concentration in plasma after a standard intravenous dose is in the range of $\sim 200 \mu \mathrm{M}$ with an initial half-life of $\sim 1$ hour and concentrations in excess of $20 \mu \mathrm{M}$ sustained for $\sim 3$ hours (Latz et al., 2006). Assuming even a neutral intratumoral $\mathrm{pH}$, and a pemetrexed influx $\mathrm{K}_{\mathrm{t}}$ of $12-15 \mu \mathrm{M}$ at $\mathrm{pH}$ 7.4 , there should be substantial delivery and free intracellular drug levels mediated by PCFT over this interval. However, since the usual interstitial $\mathrm{pH}$ of tumors is acidic, PCFTmediated pemetrexed influx and free intracellular levels would be much greater resulting in increased formation of active pemetrexed polyglutamate derivatives (Wike-Hooley et al., 1984; Tannock and Rotin, 1989; Hashim et al., 2011).

\section{Authorship Contributions}

Participated in research design: Zhao, Spray, Goldman.

Conducted experiments: Zhao, Najmi, Aluri.

Performed data analysis: Zhao, Najmi, Aluri, Spray, Goldman.

Wrote or contributed to the writing of the manuscript: Zhao, Goldman.

\section{References}

Anderson CM and Thwaites DT (2010) Hijacking solute carriers for proton-coupled drug transport. Physiology (Bethesda) 25:364-377.

Assaraf YG (2006) The role of multidrug resistance efflux transporters in antifolate resistance and folate homeostasis. Drug Resist Updat 9:227-246.

Benz R and McLaughlin S (1983) The molecular mechanism of action of the proton ionophore FCCP (carbonylcyanide p-trifluoromethoxyphenylhydrazone). Biophys $J$ 41:381-398.

Chattopadhyay S, Moran RG, and Goldman ID (2007) Pemetrexed: biochemical and cellular pharmacology, mechanisms, and clinical applications. Mol Cancer Ther 6 404-417.

Chattopadhyay S, Zhao R, Krupenko SA, Krupenko N, and Goldman ID (2006) The inverse relationship between reduced folate carrier function and pemetrexed activity in a human colon cancer cell line. Mol Cancer Ther 5:438-449.

Desmoulin SK, Hou Z, Gangjee A, and Matherly LH (2012) The human protoncoupled folate transporter: biology and therapeutic applications to cancer. Cancer Biol Ther 13:1355-1373.

Desmoulin SK, Wang L, Hales E, Polin L, White K, Kushner J, Stout M, Hou Z, Cherian C, Gangjee A, et al. (2011) Therapeutic targeting of a novel 6-substituted pyrrolo [2,3-d]pyrimidine thienoyl antifolate to human solid tumors based on selective uptake by the proton-coupled folate transporter. Mol Pharmacol 80 1096-1107.

Diop-Bove NK, Wu J, Zhao R, Locker J, and Goldman ID (2009) Hypermethylation of the human proton-coupled folate transporter (SLC46A1) minimal transcriptiona regulatory region in an antifolate-resistant HeLa cell line. Mol Cancer Ther 8 : $2424-2431$.

Gaillard S and Dupont JL (1990) Ionic control of intracellular pH in rat cerebellar Purkinje cells maintained in culture. $J$ Physiol 425:71-83.

Giovannetti E, Zucali PA, Assaraf YG, Funel N, Gemelli M, Stark M, Thunnissen E, Hou Z, Muller IB, Struys EA, et al. (2017) Role of proton-coupled folate transporter in pemetrexed resistance of mesothelioma: clinical evidence and new pharmacological tools. Ann Oncol 28:2725-2732.

Habeck LL, Mendelsohn LG, Shih C, Taylor EC, Colman PD, Gossett LS, Leitner TA Schultz RM, Andis SL, and Moran RG (1995) Substrate specificity of mammalian folylpolyglutamate synthetase for 5,10-dideazatetrahydrofolate analogs. Mol Pharmacol 48:326-333.

Hashim AI, Zhang X, Wojtkowiak JW, Martinez GV, and Gillies RJ (2011) Imaging $\mathrm{pH}$ and metastasis. NMR Biomed 24:582-591.

Hou Z, Gattoc L, O'Connor C, Yang S, Wallace-Povirk A, George C, Orr S, Polin L White K, Kushner J, et al. (2017) Dual targeting of epithelial ovarian cancer via folate receptor $\alpha$ and the proton-coupled folate transporter with 6-substituted pyrrolo[2,3-d]pyrimidine antifolates. Mol Cancer Ther 16:819-830.

Kronn D and Goldman ID (2017) Hereditary folate malabsorption, in GeneReviews (Pagon RA, Adam MP, Ardinger HH, Wallace SE, Amemiya A, Bean LJH, Bird TD, Dolan CR, Fong CT, Smith RJH, et al., ed) University of Washington, Seattle, Washington.
Latz JE, Chaudhary A, Ghosh A, and Johnson RD (2006) Population pharmacokinetic analysis of ten phase II clinical trials of pemetrexed in cancer patients. Cancer Chemother Pharmacol 57:401-411.

Levraut J, Giunti C, Ciebiera JP, de Sousa G, Ramhani R, Payan P, and Grimaud D (2001) Initial effect of sodium bicarbonate on intracellular $\mathrm{pH}$ depends on the extracellular nonbicarbonate buffering capacity. Crit Care Med 29:1033-1039.

Masereel B, Pochet L, and Laeckmann D (2003) An overview of inhibitors of $\mathrm{Na}(+) / \mathrm{H}$ (+) exchanger. Eur J Med Chem 38:547-554

Matherly LH, Hou Z, and Gangjee A (2018) The promise and challenges of exploiting the proton-coupled folate transporter for selective therapeutic targeting of cancer. Cancer Chemother Pharmacol 81:1-15.

Nakazato K and Hatano Y (1991) Monensin-mediated antiport of $\mathrm{Na}+$ and $\mathrm{H}+$ across liposome membrane. Biochim Biophys Acta 1064:103-110.

Park KS, Jo I, Pak K, Bae SW, Rhim H, Suh SH, Park J, Zhu H, So I, and Kim KW (2002) FCCP depolarizes plasma membrane potential by activating proton and $\mathrm{Na}+$ currents in bovine aortic endothelial cells. Pflugers Arch 443:344-352.

Qiu A, Jansen M, Sakaris A, Min SH, Chattopadhyay S, Tsai E, Sandoval C, Zhao R Akabas MH, and Goldman ID (2006) Identification of an intestinal folate transporter and the molecular basis for hereditary folate malabsorption. Cell 127: 917-928.

Sharif KA, Moscow JA, and Goldman ID (1998) Concentrating capacity of the human reduced folate carrier (hRFC1) in human ZR-75 breast cancer cell lines. Biochem Pharmacol 55:1683-1689.

Shih C, Chen VJ, Gossett LS, Gates SB, MacKellar WC, Habeck LL, Shackelford KA Mendelsohn LG, Soose DJ, Patel VF, et al. (1997) LY231514, a pyrrolo[2,3-d]pyrimidine-based antifolate that inhibits multiple folate-requiring enzymes. Cancer Res 57:1116-1123.

Smith KM, Slugoski MD, Loewen SK, Ng AM, Yao SY, Chen XZ, Karpinski E, Cass CE, Baldwin SA, and Young JD (2005) The broadly selective human Na+/nucleoside cotransporter (hCNT3) exhibits novel cation-coupled nucleoside transport characteristics. J Biol Chem 280:25436-25449.

Stein MA, Mathers DA, Yan H, Baimbridge KG, and Finlay BB (1996) Enteropathogenic Escherichia coli markedly decreases the resting membrane potential of Caco-2 and HeLa human epithelial cells. Infect Immun 64:4820-4825.

Tannock IF and Rotin D (1989) Acid pH in tumors and its potential for therapeutic exploitation. Cancer Res 49:4373-4384.

Visentin M, Diop-Bove N, Zhao R, and Goldman ID (2014) The intestinal absorption of folates. Annu Rev Physiol 76:251-274.

Wike-Hooley JL, Haveman J, and Reinhold HS (1984) The relevance of tumour pH to the treatment of malignant disease. Radiother Oncol 2:343-366.

Wolosin JM, Bonanno JA, Hanzel D, and Machen TE (1991) Bicarbonate transport mechanisms in rabbit ciliary body epithelium. Exp Eye Res 52:397-407.

Young JD, Yao SY, Baldwin JM, Cass CE, and Baldwin SA (2013) The human concentrative and equilibrative nucleoside transporter families, SLC28 and SLC29. Mol Aspects Med 34:529-547.

Zhao R, Aluri S, and Goldman ID (2017) The proton-coupled folate transporter (PCFT-SLC46A1) and the syndrome of systemic and cerebral folate deficiency of infancy: hereditary folate malabsorption. Mol Aspects Med 53:57-72.

Zhao R, Diop-Bove N, and Goldman ID (2014) Enhanced receptor-mediated endocytosis and cytotoxicity of a folic acid-desacetylvinblastine monohydrazide conjugate in a pemetrexed-resistant cell line lacking folate-specific facilitative carriers but with increased folate receptor expression. Mol Pharmacol 85:310-321.

Zhao R, Gao F, Hanscom M, and Goldman ID (2004a) A prominent low-pH methotrexate transport activity in human solid tumors: contribution to the preservation of methotrexate pharmacologic activity in HeLa cells lacking the reduced folate carrier. Clin Cancer Res 10:718-727.

Zhao R and Goldman ID (2013a) Folate and thiamine transporters mediated by facilitative carriers (SLC19A1-3 and SLC46A1) and folate receptors. Mol Aspects Med 34:373-385

Zhao R and Goldman ID (2013b) The proton-coupled folate transporter: physiological and pharmacological roles. Curr Opin Pharmacol 13:875-880.

Zhao R, Hanscom M, Chattopadhyay S, and Goldman ID (2004b) Selective preservation of pemetrexed pharmacological activity in HeLa cells lacking the reduced folate carrier: association with the presence of a secondary transport pathway. Cancer Res 64:3313-3319.

Zhao R, Matherly LH, and Goldman ID (2009) Membrane transporters and folate homeostasis: intestinal absorption and transport into systemic compartments and tissues. Expert Rev Mol Med 11:e4

Zhao R, Qiu A, Tsai E, Jansen M, Akabas MH, and Goldman ID (2008) The protoncoupled folate transporter: impact on pemetrexed transport and on antifolates activities compared with the reduced folate carrier. Mol Pharmacol 74:854-862.

Zhao R, Visentin M, Suadicani SO, and Goldman ID (2013) Inhibition of the protoncoupled folate transporter (PCFT-SLC46A1) by bicarbonate and other anions. Mol Pharmacol 84:95-103.

Address correspondence to: Dr. I. David Goldman, Department of Medicine and Molecular Pharmacology, Albert Einstein Cancer Center, Chanin 2, 1300 Morris Park Ave., Bronx, NY 10461. E-mail: i.david.goldman@einstein. yu.edu 